\title{
Unusual presentation of high-grade neuroendocrine carcinoma of the Urinary bladder with small-cell and large-cell features
}

\author{
Vitor Fiorin de Vasconcellos ${ }^{a}$, João Lapa Lima Trancoso ${ }^{\mathrm{b}}$, Aloísio Felipe-Silvac, \\ Angélica Braz Simões ${ }^{c}$, Pedro José dos Santos Netod, Oscar Eduardo Hidetoshi Fugitae, \\ Carla Rachel Ono $f$, Carlos Alberto Buchpiguel ${ }^{f}$
}

Vasconcellos VF, Trancoso JLL, Felipe-Silva A, et al. Unusual presentation of high-grade neuroendocrine carcinoma of the Urinary bladder with small-cell and large-cell features. Autopsy Case Rep [Internet]. 2013; 3(3): 67-75. http://dx.doi. org/10.4322/acr.2013.028

\section{ABSTRACT}

High-grade neuroendocrine carcinoma of the urinary bladder comprehends small-cell and large-cell variants. It is a rare and aggressive neoplasm, mostly diagnosed in advanced stages. It is more frequently encountered among Caucasian men in the sixth decade of life. Urinary symptoms are the most common clinical presentation. Diagnosis is generally not troublesome once the lesions are easily detectable by imaging exams and cystoscopy. This neoplasia is associated with tobacco smoking, and is frequently associated with other carcinomatous components such as urothelial carcinoma, adenocarcinoma, and sarcomatoid carcinoma. The authors report a case of an apparently healthy female patient who presented cervical lymph node enlargement not accompanied by systemic symptoms. The supraclavicular lymph node biopsy revealed metastatic small cell carcinoma. The computed tomography scan showed a bladder wall nodular thickening, enlarged lymph nodes along the iliac, periaortic, mediastinal, cervical and supraclavicular chains, as well as an insufflating lytic bone lesion in the right iliac wing. The positron emission tomography-fluorodeoxyglucose (PETFDG) added to these findings, the presence of a paraesophageal lymph node, lymphadenomegaly in the gluteal region and a vertebral lytic lesion in T10. Resected specimen of the bladder tumor revealed a high-grade neuroendocrine carcinoma with small-cell and large-cell features.

Keywords: Carcinoma, Small Cell; Carcinoma, Neuroendocrine; Urinary Bladder Neoplasm; Lymphatic Diseases.

\footnotetext{
${ }^{a}$ Department of Internal Medicine, Hospital das Clínicas, Faculdade de Medicina,Universidade de São Paulo, São Paulo/SP - Brazil.

b Department of Internal Medicine, Faculdade de Medicina, Universidade de São Paulo, São Paulo/SP - Brazil.

${ }^{c}$ Anatomic Pathology Service, Hospital Universitário, Universidade de São Paulo, São Paulo/SP - Brazil.

d Diagnostic Imaging Service, Hospital Universitário, Universidade de São Paulo, São Paulo/SP - Brazil.

e Department of Surgery, Hospital Universitário, Universidade de São Paulo, São Paulo/SP - Brazil.

f Institut of Radiology, Hospital das Clínicas, Faculdade de Medicina, Universidade de São Paulo, São Paulo/SP - Brazil.
}

Copyright $\odot 2013$ Autopsy and Case Reports - This is an Open Access article distributed of terms of the Creative Commons Attribution NonCommercial License (http://creativecommons.org/licenses/by/3.0/) which permits unrestricted non-commercial use, distribution, and reproduction in any médium provided article is properly cited. 


\section{CASE REPORTS}

A 63-year-old female patient sought medical attention because of a left cervical bulging for the last 2 weeks and right flank pain radiating to the dorsum. She denied fever, weight loss, or any gastrointestinal or genitourinary complaints. The past medical history included hypertension and previous tabagism. The physical examination of the patient's cervical region showed the presence of enlarged lymph nodes along the left anterior and posterior cervical chains and a firm mass bulging on the left supraclavicular fossa corresponding to a cluster of enlarged lymph nodes. The cervical computed tomography (CT) scans showed lymphadenomegaly on the cervical (levels III and IV), supraclavicular and upper mediastinal regions, measuring up to $3.0 \times 2.3 \mathrm{~cm}$, determining contralateral deviation of the trachea (Figure 1).

The patient was submitted to a cervical lymph node biopsy, which revealed the presence of metastatic small-cell neuroendocrine carcinoma (Figure 2).

CT scans showed mediastinal (Figure 3), and periaortic (Figure 4), pericaval, common iliac, and right internal and external iliac chains (Figure 5) lymph node enlargements.

Some lymph nodes showed a heterogeneous aspect, which was probably related to necrotic liquefaction. On the right iliac wing, an insufflating, lytic lesion disrupting the cortical bone was present (Figure 6). No other bone lesions were found.

The CT scan showed a $2.0 \mathrm{~cm}$-nodular bladder wall thickening on the right posterolateral wall (Figure 7). The ultrasonographic examination revealed a vegetating lesion at the same area, without evidence of muscular extension.

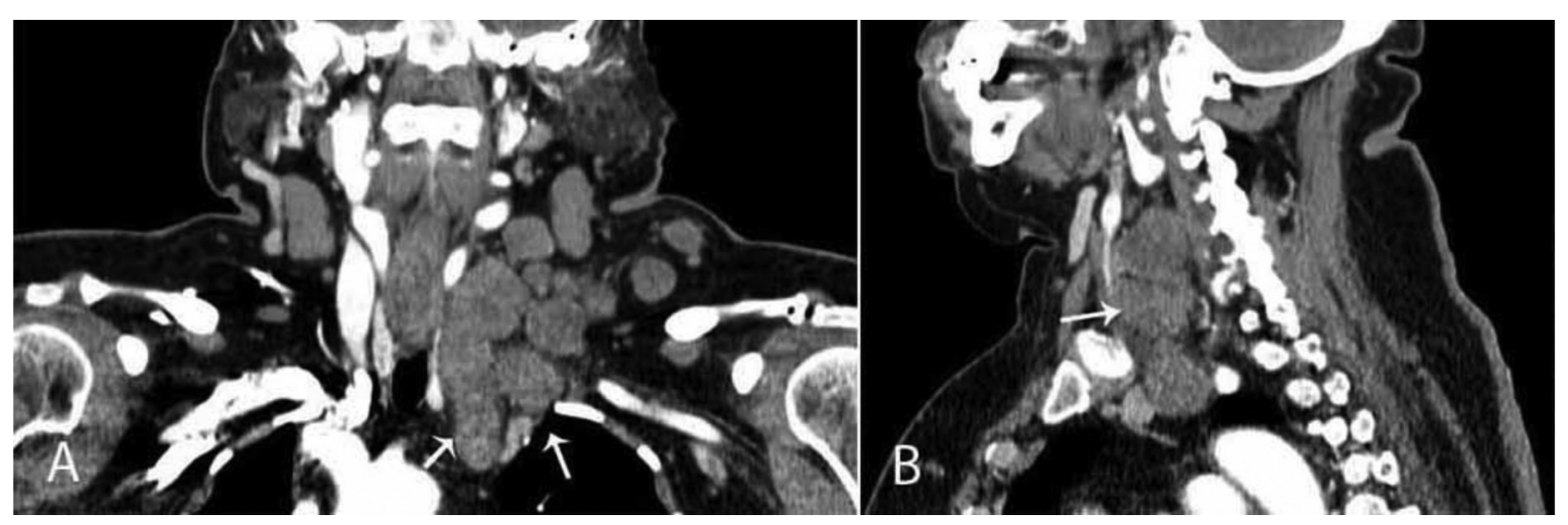

Figure 1 - Computed tomography (CT) of the cervical region. A - Coronal reformation; B - Sagittal reformation, showing lymphadenomegaly (arrows) on the left side of the neck and superior mediastinum.
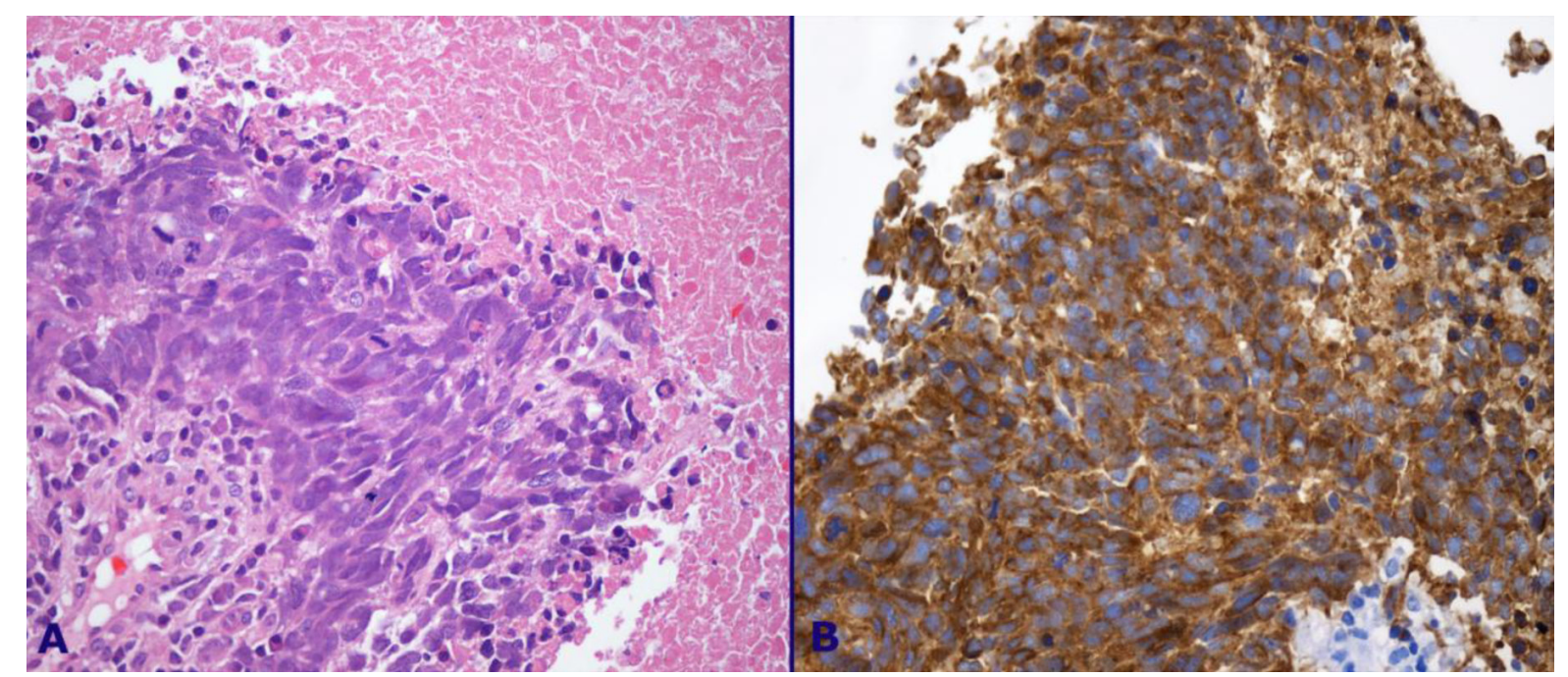

Figure 2 - Photomicrography of the lymph node biopsy with metastatic tumor. A - Small cells with nuclear molding, scant cytoplasm, and mitotic figures in a necrotic background (H\&E, 400X); B - Positive immunohistochemistry staining for synaptophysin (400X). 


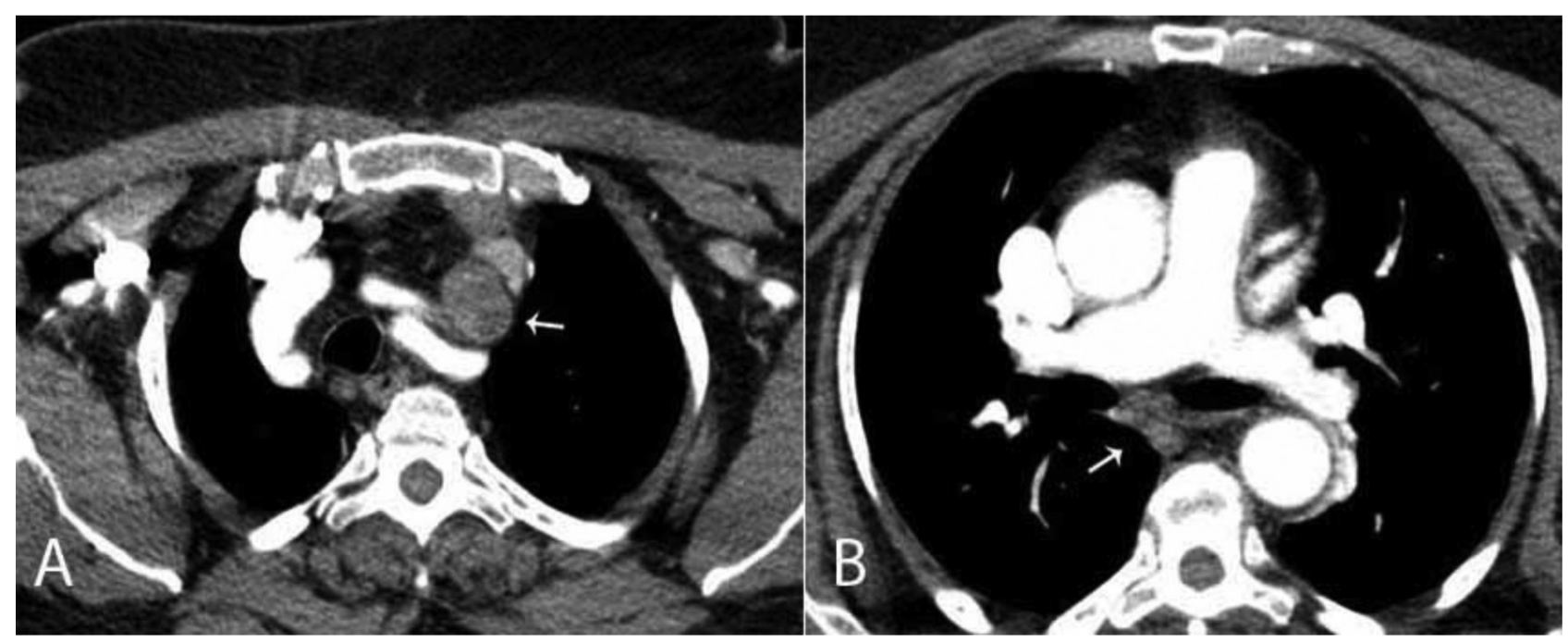

Figure 3-Axial computed tomography of the thorax showing mediastinal lymph nodes enlargement (arrows). A - Involving the pre vascular space; B - The carinal topography.

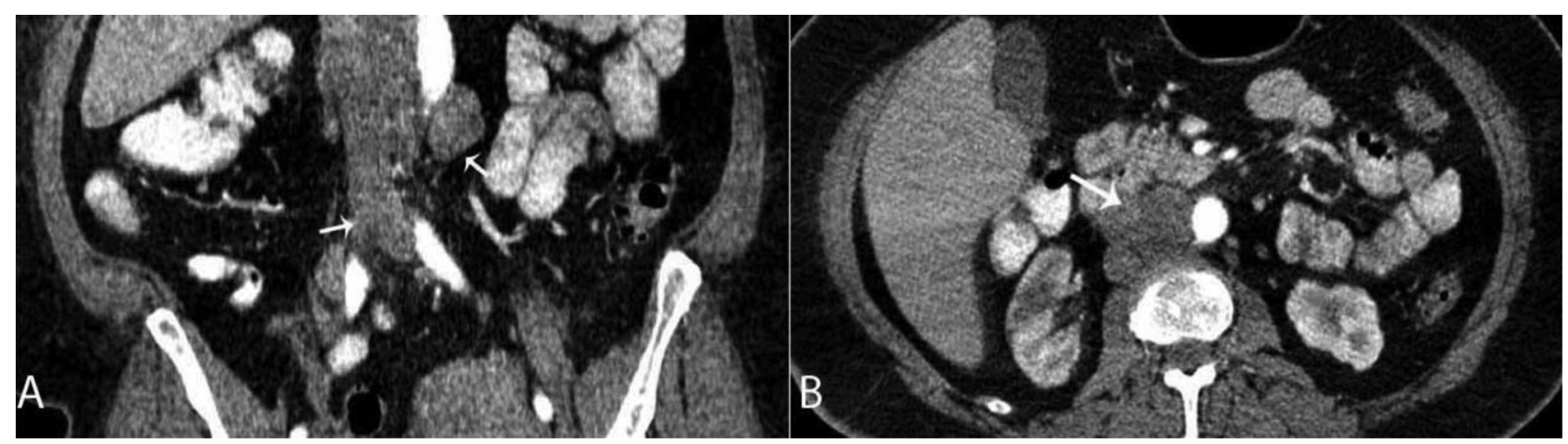

Figure 4 - CT of the abdomen. A - Coronal reformation; B - Axial plane - both showing periaortic lymphadenomegaly (arrows).

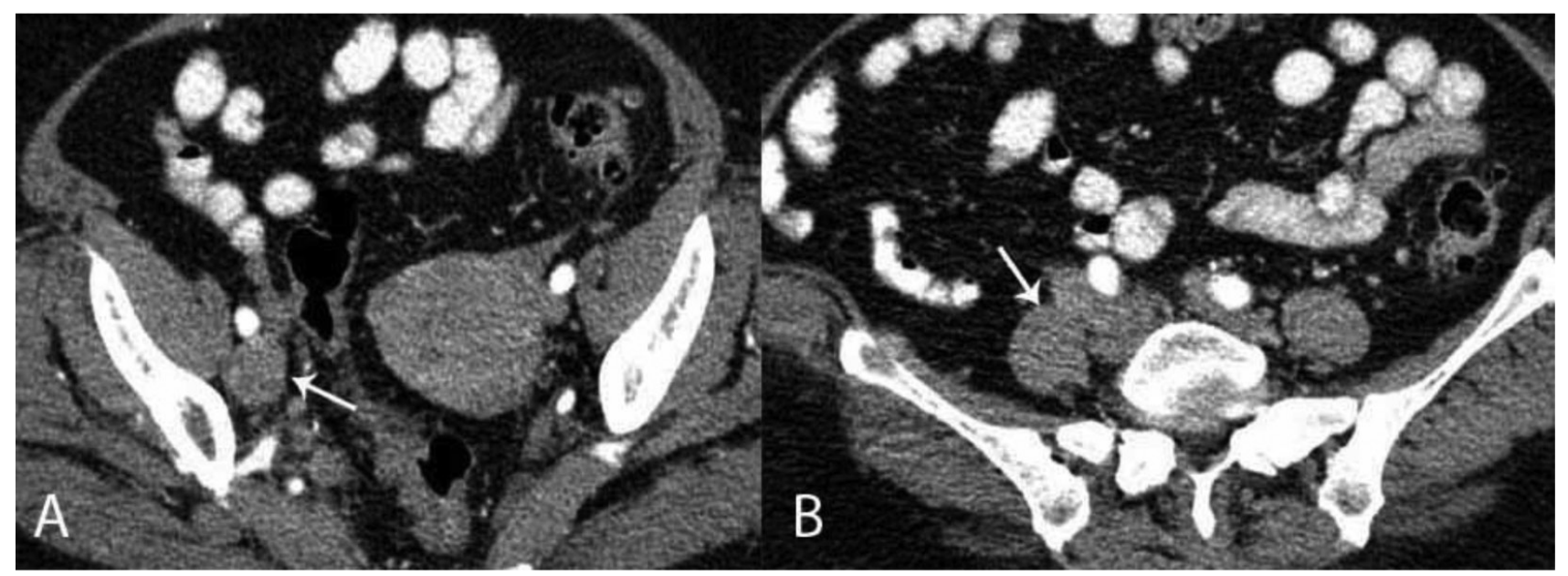

Figure $\mathbf{5}$ - Axial CT of the pelvis. A - Lymphadenomegaly along the external iliac chain; $\mathbf{B}$ - along the common iliac chain.

The patient underwent transurethral resection of the bladder lesion. The histopathological and immunohistochemical examination confirmed the diagnosis of a high-grade neuroendocrine carcinoma. The resected tumor was mostly composed of infiltrative, solid sheets of small and intermediate cells, often overlapping with scanty cytoplasm, similar to the metastatic sample on cervical lymph node (Figure 8A). Chromatin was granular with small or absent nucleoli and numerous mitotic figures were seen. In other areas (about $20 \%$ ), tumor cells had larger and more pleomorphic nuclei, 


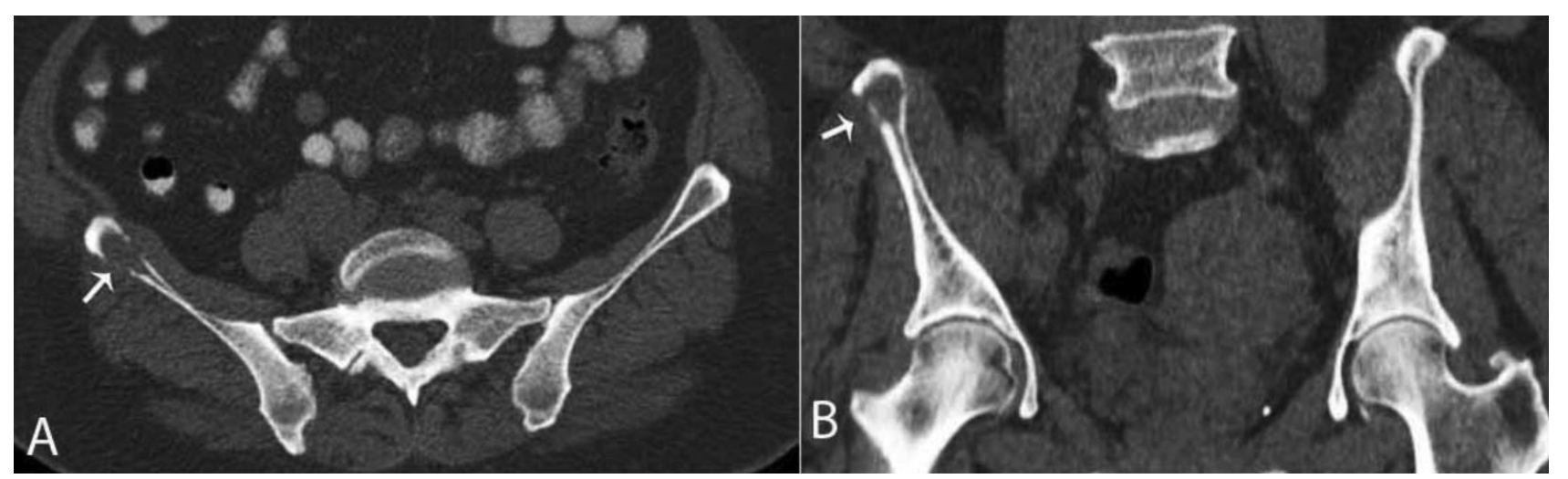

Figure 6-CT of the pelvis, bone window. A - Axial plane; B - Coronal reformation, both showing a lytic bone lesion (arrows) with a slight soft tissue involvement in the right iliac wing.

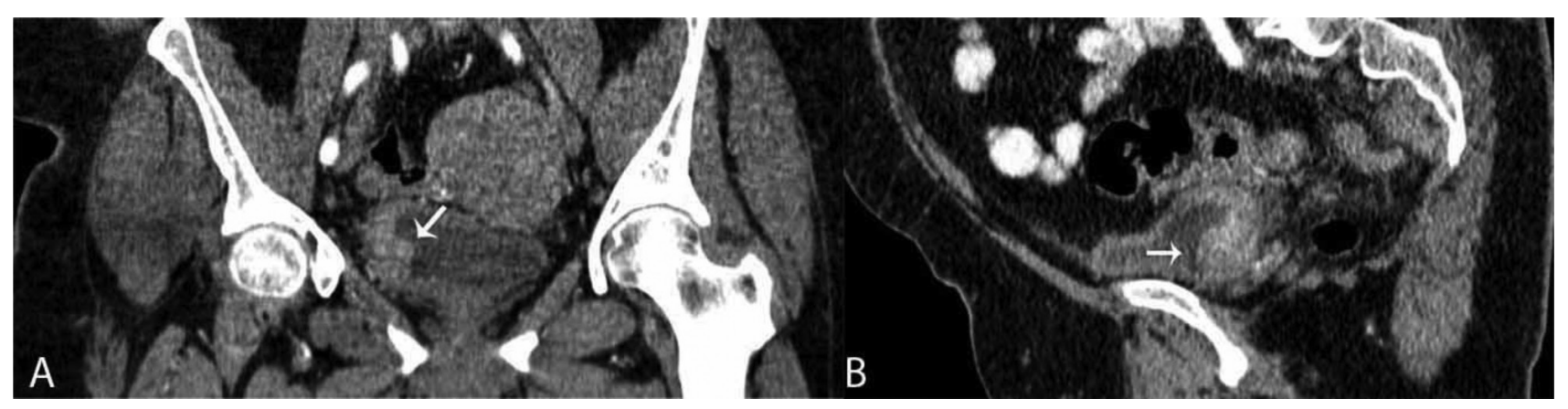

Figure 7 - CT of the pelvis. A - Coronal reformation; B - Sagittal reformation, both showing nodular thickening of the right posterolateral wall of the urinary bladder (arrows).

with prominent nucleoli and some multinucleated cells. These findings were interpreted as a large-cell neuroendocrine carcinoma component (Figure 8B, $8 \mathrm{C}, 8 \mathrm{D})$.

Areas of adenocarcinoma with goblet cells and micropapillary urothelial carcinoma were present in about $10 \%$ of the specimen (Figure 9). Invasion of the urinary bladder muscular wall and lymphatics was evident on histology. The immunohistochemical staining of both pathological specimens are summarized in Table 1. The focal positivity for the p63 antibody in the metastasis was suggestive of a squamous or urothelial epithelium as the primary lesion. During the hospitalization, the patient did not present any urinary symptom or any compressive symptom associated with lymphadenopathy.

Complementary staging was held by a positron emission tomography-fluorodeoxyglucose (PET-FDG) examination from the base of the skull to the thighs, which revealed increased glycolytic metabolism in area of focal thickening of the urinary bladder wall, compatible with primary neoplastic lesion. There was an increase of glycolytic metabolism in multiple cervical lymph nodes, mediastinal, abdominal and pelvic lymph nodes, consistent with secondary involvement. PET-FDG also showed lytic bone lesions with increased glycolytic metabolism in the spine and the right iliac, compatible with secondary metastatic involvement. This exam seemed to be superior to $\mathrm{CT}$ alone by the demonstration of the paraesophageal lymph node, which was not enlarged (Figure 10A and B), the lymphadenomegaly between the right muscles gluteus maximus and gluteus medius (Figure 10C and D), as well as the presence of the vertebral Iytic lesion in T10. The remaining lesions depicted on PET-FDG were also detected by the CT. Data obtained by PET-FDG were consistent with the poor differentiation and the high mitotic index (Ki-67 between $60 \%-70 \%$ ). The primary neoplasm became evident after the administration of furosemide, when FDG diluted with urine, highlighted the bladder lesion (Figure $10 \mathrm{E}$ and $\mathrm{F}$ ).

With this diagnosis and staging, the patient was discharged for further treatment at an oncologic center. 


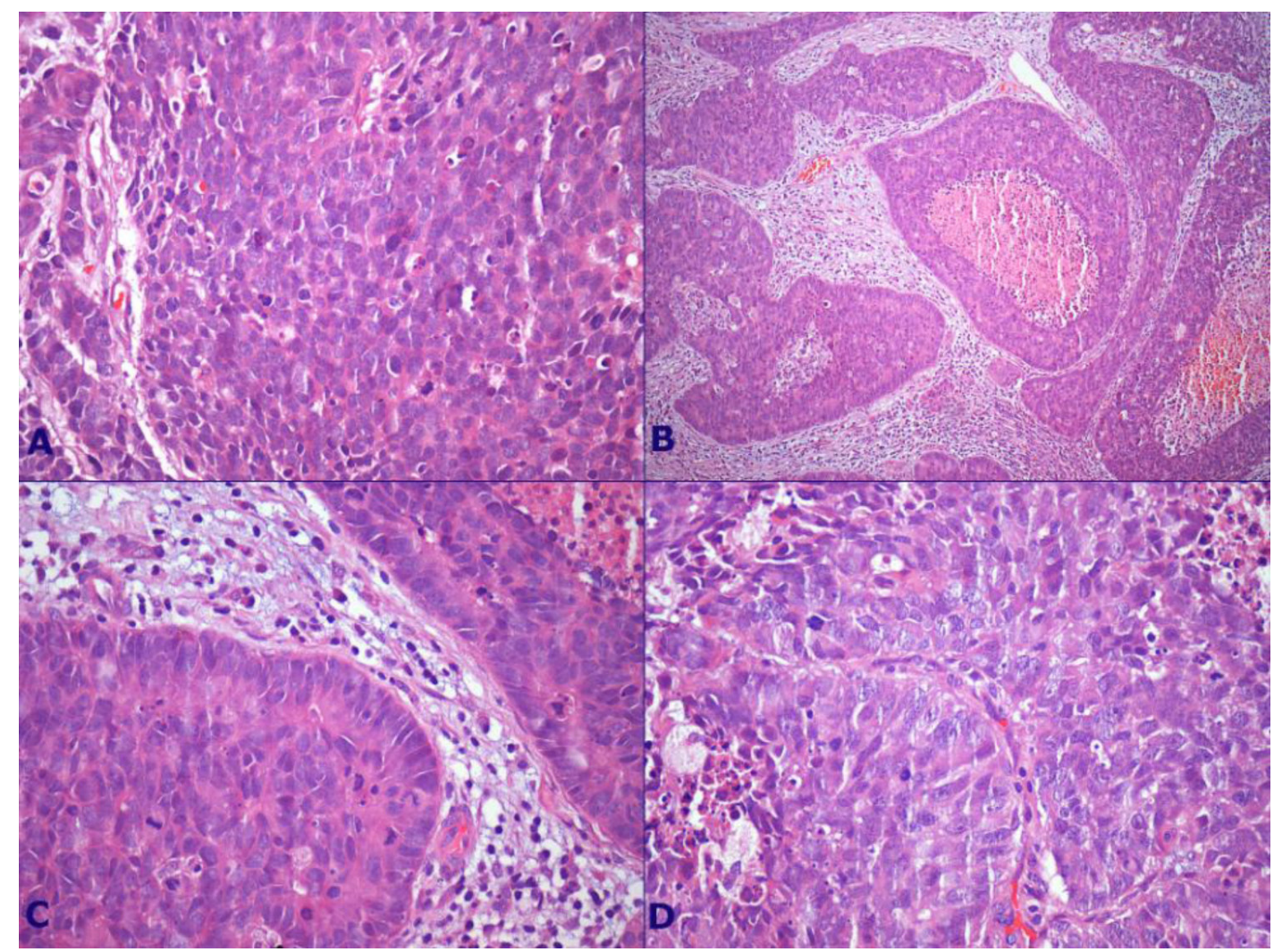

Figure 8 - Photomicrography of the bladder tumor. A - Areas of small-cell neuroendocrine carcinoma, (H\&E, 400X); B - Areas of large-cell neuroendocrine carcinoma with comedonecrosis (H\&E, 100X); C - Areas of large-cell neuroendocrine carcinoma with nuclear palisading with more abundant cytoplasm (H\&E, 400X); D - Larger and more pleomorphic nuclei, with prominent nucleoli (H\&E, 400X) were consistent with a largecell neuroendocrine carcinoma component (compare to small-cell carcinoma in A).

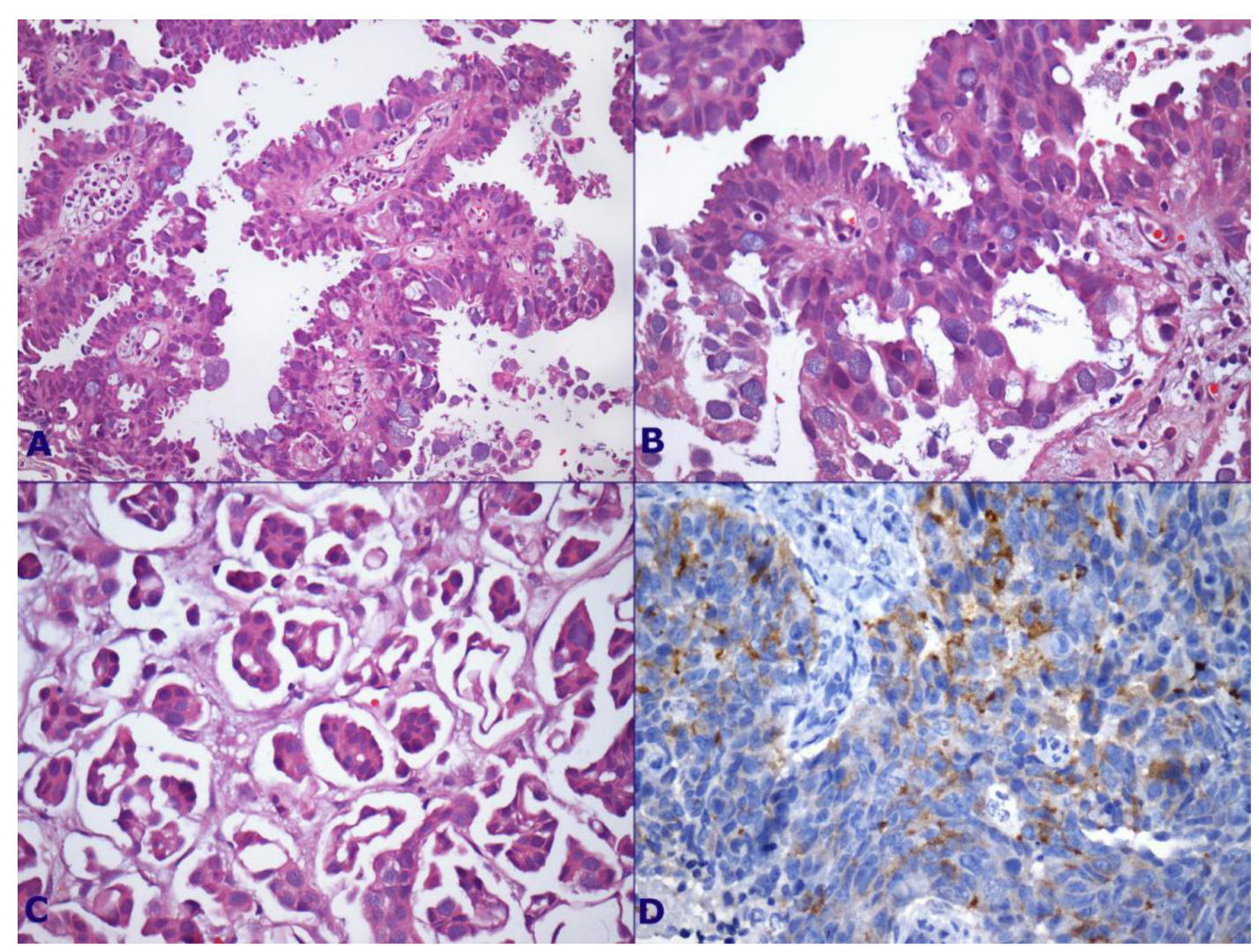

Figure 9 - Photomicrography of the bladder tumor. A - Adenocarcinoma component (H\&E, 200X); B - Goblet cells in the adenocarcinoma component (H\&E, 400X); C - Micropapillary component (H\&E, 400X); D - Chromogranin-positive immunohistochemistry in solid areas with neuroendocrine pattern (400X). 
A

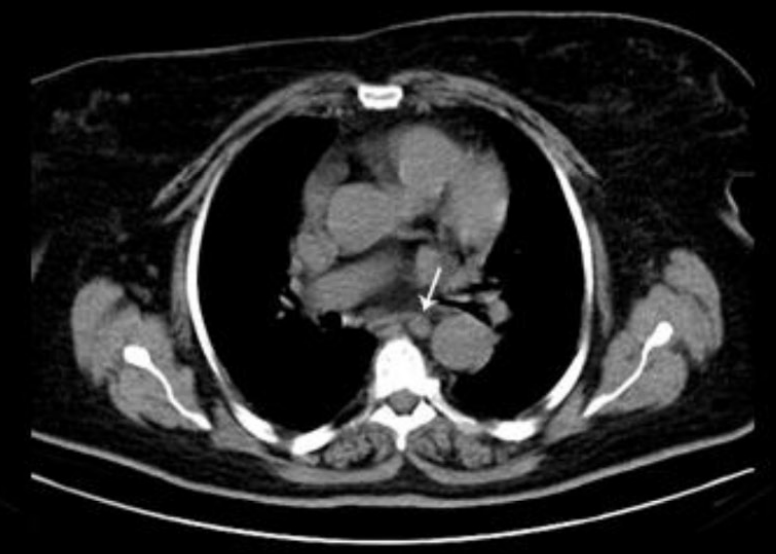

C

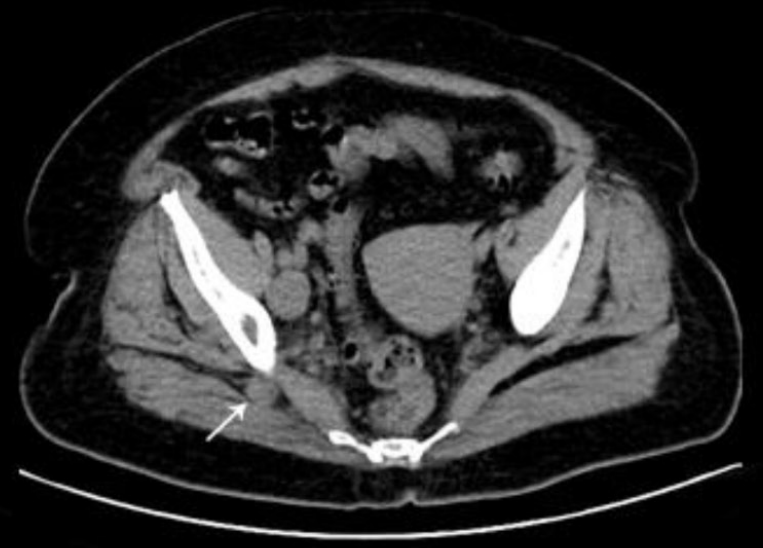

$E$

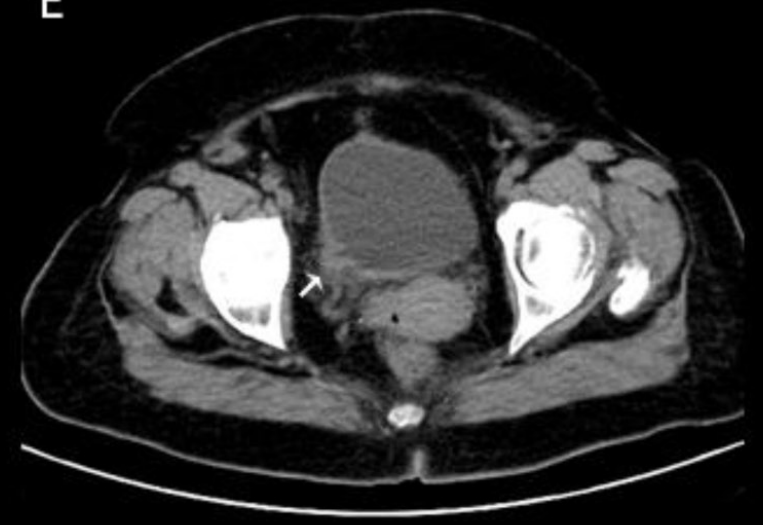

B

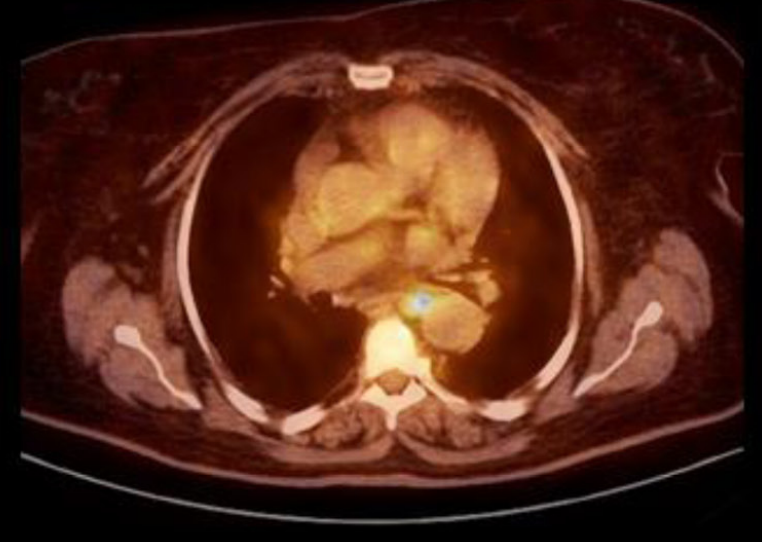

D

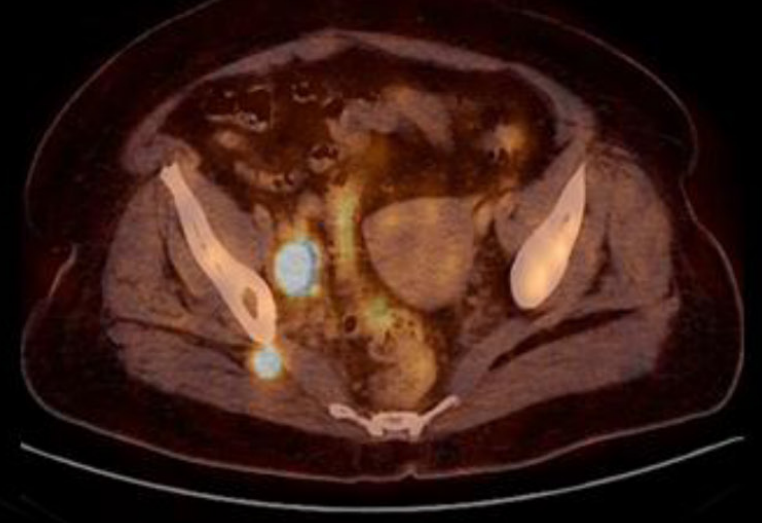

$\mathrm{F}$

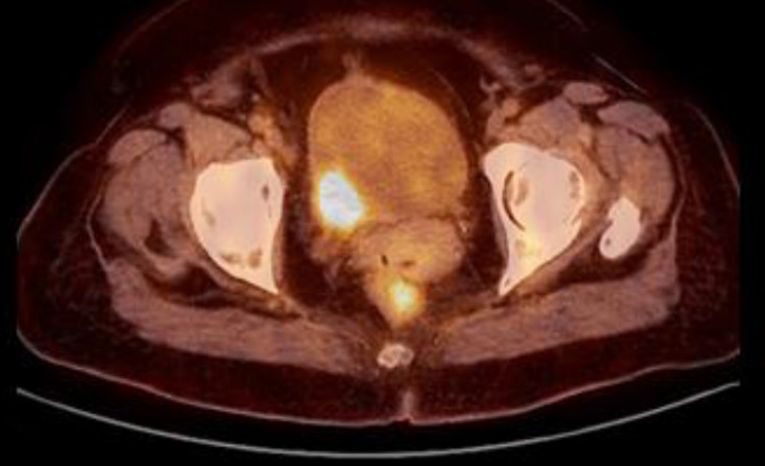

Figure 10 - PET-FDG image acquisition and CT. A and B disclose a metastatic paraesophageal lymph node (arrow); $\mathbf{C}$ and $\mathbf{D}$ show a metastatic lymph node between the gluteus maximus and gluteus medius muscles (arrow); $\mathbf{E}$ and $\mathbf{F}$ show the bladder lesion after furosemide administration (arrow). 
Table 1 - Immunohistochemical panel

\begin{tabular}{|c|c|c|}
\hline \multirow[t]{2}{*}{ Antigen } & \multicolumn{2}{|c|}{ Result } \\
\hline & $\begin{array}{l}\text { Lymph node } \\
\text { metastasis }\end{array}$ & $\begin{array}{c}\text { Urinary bladder } \\
\text { primary }\end{array}$ \\
\hline$A E 1+A E 3$ & Negative & Positive focal \\
\hline Vimentin & Positive focal & NA \\
\hline Chromogranin A & Positive focal & Positive focal \\
\hline Synaptophysin & Positive & Positive \\
\hline CK7 & Negative & $\begin{array}{c}\text { Positive } \\
\text { (differentiated) }\end{array}$ \\
\hline CK20 & Negative & $\begin{array}{c}\text { Positive (focal } \\
\text { adenocarcinoma) }\end{array}$ \\
\hline TTF-1 & Negative & NA \\
\hline CDX-2 & Negative & NA \\
\hline Ki67 & Positive $60-70 \%$ & NA \\
\hline p63 & Positive focal & NA \\
\hline EMA & Positive focal & NA \\
\hline 35Beta H11 & Negative & Positive \\
\hline CD99 & Positive & NA \\
\hline CD56 & Positive & NA \\
\hline S100 & Negative & NA \\
\hline CEA & NA & $\begin{array}{c}\text { Positive (focal } \\
\text { adenocarcinoma) }\end{array}$ \\
\hline
\end{tabular}

NA - non available.

\section{DISCUSSION}

Small-cell carcinoma (SmCC), also called undifferentiated carcinoma, anaplasic SmCC, neuroendocrine SmCC or "oat-cell" carcinoma, is a well-established histological variant of epithelial tumors of the lung, first described in $1926 .{ }^{1}$ Since 1930, after the first description of an extrapulmonary small-cell carcinoma by Duguid et al., ${ }^{2}$ this neoplasia has been reported in many anatomical locations within the body like the esophagus, other organs of the gastrointestinal tract, head and neck and genitourinary tract. ${ }^{3}$

In the most recent consensus of the World Health Organization (WHO) and the International Agency for research on Cancer (IARC), neuroendocrine tumors (NETs), formerly called carcinoid tumors, are classified separately from neuroendocrine carcinomas (NECs) of lowand high-grade malignancy. "Atypical carcinoids," accompanied by local invasion, lymph node metastases, as well as distant metastases, correspond to low-grade NECs, whereas the classic small-cell carcinomas are classified as high-grade NECs. ${ }^{4}$
In 1981, Cramer et al. ${ }^{5}$ reported the first case of small-cell carcinoma of the urinary bladder (SmCCB), in a 69-year-old man with urinary bladder irritability and hematuria. Despite the significant number of reports on this neoplasia variant since then, SmCCB remains rare and corresponds to $0.5-0.7 \%$ of all urinary bladder neoplasms. ${ }^{6,7}$ The reported incidence is less than $1-9 / 1,000,000$ inhabitant. From 1980 until 2011, fewer than 1000 cases of SmCCB have been reported. ${ }^{7}$

Similarly to the urothelial carcinoma of the urinary bladder (UCB), the SmCCB is more frequent among men than women $(76 \%$ and $24 \%$, respectively). Caucasians are involved in $91 \%$ of the cases with the median age at diagnosis of 73 years, ${ }^{8}$ and $65 \%$ of the cases present a history of tobacco smoking. ${ }^{9}$ The most common clinical features are related to the urinary tract, including hematuria, dysuria, nocturia, frequency, obstructive symptoms, and hypogastric and/or pelvic pain. ${ }^{9}$ Among the NETs of the urinary bladder, a few cases of carcinoid tumors show immunoreactivity for polypeptides, such as calcitonin and subunit of $\beta$-human chorionic gonadotropin, without clinical expression. ${ }^{10,11}$ Paraneoplastic syndromes, such as ectopic secretion of adrenocorticotropic hormone (ACTH) and hypercalcemia, are scarcely found among SmCCB, ${ }^{12,13}$ differently from the SmCC of the lung. ${ }^{7}$ In the case reported here, urinary symptoms and the lack of clinical and laboratory systemic involvement routinely found in advanced stage of neoplasias were noticeably absent. Considering the clinical presentation as isolated cervical and supraclavicular lymph adenomegaly in an apparently healthy patient, the diagnosis of bladder tumor was not raised among the differential diagnosis. Only after the incidental finding of the urinary bladder wall thickening on $\mathrm{CT}$ examination was this diagnosis taken into account. The histopathological examination of the lymph node biopsy could only provide the diagnosis of metastatic small-cell carcinoma of unknown origin. The sole epidemiological data favoring urinary bladder neoplasm was tabagism.

The biological behavior of SmCCB is characterized by its higher aggressiveness and consequently by a poorer prognosis when compared to the urothelial carcinoma of the bladder. ${ }^{6}$ Therefore, SmCCB usually presents at diagnosis as an advanced metastatic undifferentiated disease (high-grade). In a series of 88 cases conducted at the MD Anderson Cancer Center over 18 years, ${ }^{14}$ only $4.5 \%$ ( $n=4$ patients) were diagnosed in early 
stage (Ta/T1), while $40.1 \%(n=36)$ were $T 2 ; 28.3 \%$ $(n=25)$ as T3-T4a (stage III), and $26.1 \%(n=23)$ as T4b-M1 (stage IV). The spreading pattern typically involves the lymph nodes, the liver, and bones, which is similar to urothelial carcinoma of the bladder. ${ }^{9}$ Central nervous system metastases are less frequent when compared with SmCC of the lung. ${ }^{15}$

In the case reported here, it was surprising that regional disease or contiguity dissemination was not observed facing the presence of extensive lymphatic spread. The lymphatic involvement ascended from the right internal and external iliac chain to the retroperitoneal, mediastinal, and supraclavicular chains. At the moment of the diagnosis, hepatic or pulmonary metastases were not present at CT, PET-FDG and neither by biochemical determinations. The finding of a lytic and insufflating bone lesion at the right iliac wing detected by CT, and a vertebral lesion on PET-FDG represented the sole extranodal metastases. The neuroendocrine carcinoma (NEC) staging usually do not benefit from PET-FDG, due to their mild avidity for glucose, which show a low glycolytic metabolism. In this case it was useful because of the high mitotic index expressed by the tumor. On the other hand, when somatostatin-analog tracers labeled with gallium-68 are used, the PET scan hast a better impact.

Small, round cells with hyperchromatic nucleus, nucleolus and chromatin dispersed in a "salt and pepper" discernible pattern, scanty cytoplasm, and organelles, characterize the smallcell carcinoma on light microscopy. Mitotic rate is usually high, as well as tumor necrosis and crush artifact. $^{7}$ Pathogenesis of SmCCB is still obscure. However, several hypotheses were proposed to explain its origin. The strongest theory suggests that the origin of SmCCB may be a multipotential common stem cell that has the ability to differentiate into various cell types depending on the influence of a specific transformation or progression-related gene. This may explain the coexistence of SmCCB with transitional cell carcinoma and the heterogeneity of the immunohistochemical staining (cytokeratin and endocrine markers). ${ }^{7}$

Many other histological types may coexist in the same tumor: adenocarcinoma, squamous cell carcinoma, and sarcomatoid urothelial carcinoma. ${ }^{15,16}$ The detection of this coexistence is important because it is associated with the prognosis. Patients with the mixed component have a median survival time, independently if metastatic or non-metastatic disease of two to three times higher than pure SmCCB histology. ${ }^{17}$

Immunohistochemistry is of paramount importance in the diagnosis of neuroendocrine SmCCB. In this setting, positive reactions to epithelial and neuroendocrine markers range from $30 \%$ to $100 \%$ of cases. It is remarkable the positivity to chromogranin A (22-89\%), synaptophysin (6776\%), CD56 and cytokeratin 8-18 (CK8-18), and some of these tumors may express TTF-1 (33\%). Less specific are cytokeratin 7 (CK7) (60\%) and epithelial membrane antigen (EMA) (80\%). ${ }^{6,7,18}$ In the case reported here, most of the tumor was represented by SmCCB associated with large-cell neuroendocrine carcinoma and a micropapillary urothelial carcinoma, showing a high mitotic activity. Besides the morphology, immunohistochemistry confirmed the diagnosis through the positive expression of chromogranin A, synaptophysin and CD56.

The 5-year survival rate for patients with SmCCB ranged from $8 \%$ to $40 \%$, no matter the staging. When properly staged, advanced disease presents a 5 -year survival of $4-10.5 \% .^{13,18}$

Large-cell neuroendocrine carcinoma of the urinary bladder is an even rarer lesion, with many overlapping clinical and pathological features with SmCCB including presentation at advanced stages and poor prognosis. ${ }^{19,20}$

In summary, we present an exceedingly rare case of a high-grade neuroendocrine carcinoma of the urinary bladder with small and large cell features, which presented clinically with cervical lymph node enlargement and no urinary symptoms.

\section{REFERENCES}

1. Cicin I, Karagol H, Uzunoglu S, et al. Extrapulmonary smallcell carcinoma compared with small-cell lung carcinoma: a retrospective single-center study. Cancer. 2007;110:106876. PMid:17614337. http://dx.doi.org/10.1002/cncr.22887

2. Duguid JB, Kennedy AM. Oat cell tumors of mediastinal glands. J Pathol Bacteriol. 1930;33:93-9.

3. Wong YN, Jack RH, Mak V, Henrik M, Davies EA. The epidemiology and survival of extrapulmonary small cell carcinoma in South East England, 1970-2004. BMC Cancer. 2009;9:209. http://dx.doi.org/10.1186/1471-2407-9-209 
4. Algaba F, Sauter G, Schoenberg MP. Small cell carcinoma. In: Eble JN, Sauter G, Epstein JI, Sesterhenn IA, editors. Pathology and genetics of tumours of the urinary system and male genital organs. Lyon: IARC Press; 2004. World Health Organization Classification of Tumours. p. 135-6.

5. Cramer SF, Aikawa M, Cebelin M. Neurosecretory granules in small cell invasive carcinoma of the urinary bladder. Cancer. 1981;47:724-30. http://dx.doi. org/10.1002/1097-0142(19810215)47:4<724::AIDCNCR2820470417>3.0.CO;2-2

6. Moretto P, Wood L, Emmenegger U, et al. Management of small cell carcinoma of the bladder: Consensus guidelines from the Canadian Association of Genitourinary Medical Oncologists (CAGMO). Can Urol Assoc J. 2013;7: e4456. PMid:23671508 PMCid:PMC3650822. http://dx.doi. org/10.5489/cuaj.220

7. Ismaili N. A rare bladder cancer - small cell carcinoma: review and update. Orphanet J Rare Dis. 2011;6:75. PMid:22078012 PMCid:PMC3253713. http://dx.doi.org/10.1186/1750-11726-75

8. Koay EJ, Teh BS, Paulino AC, Butler EB. A Surveillance, epidemiology, and end results analysis of small cell carcinoma of the bladder: epidemiology, prognostic variables, and treatment trends. Cancer. 2011;117:5325. PMid:21567387. http://dx.doi.org/10.1002/cncr.26197

9. Cheng L, Pan CX, Yang XJ. Small cell carcinoma of the urinary bladder: a clinicopathologic analysis of 64 patients. Cancer. 2004;101:957-62. PMid:15329903. http://dx.doi. org/10.1002/cncr.20456

10. Mascolo M, Altieri V, Mignogna C, et al. Calcitonin-producing well-differentiated neuroendocrine carcinoma (carcinoid tumor) of the urinary bladder: case report. BMC Cancer. 2005;5:88. http://dx.doi.org/10.1186/1471-2407-5-88

11. Martignoni G, Eble JN. Carcinoid tumors of the urinary bladder. Immunohistochemical study of 2 cases and review of the literature. Arch Pathol Lab Med. 2003;127:e22-4. PMid:12562289.

\section{Conflict of interest: None}

Submitted on: $27^{\text {th }}$ July 2013

Accept on: $14^{\text {th }}$ September 2013

Correspondence: Departamento de Clínica Médica Hospital das Clínicas da Faculdade de Medicina da USP Av. Enéas Carvalho de Aguiar, 155, São Paulo/SP - Brazil CEP: $05403-000$ - Phone: +55 (11) 3069-6412

E-mail: vitor.vasconcellos@gmail.com
12. Reyes CV, Soneru I. Small cell carcinoma of the urinary bladder with hypercalcemia. Cancer.1985;56:2530-3. http:// dx.doi.org/10.1002/1097-0142(19851115)56:10<2530::AIDCNCR2820561035>3.0.CO;2-4

13. Choong NW, Quevedo JF, Kaur JS. Small cell carcinoma of the urinary bladder. The Mayo Clinic experience. Cancer. 2005;103(6):1172-8. PMid:15700264. http://dx.doi. org/10.1002/cncr.20903

14. Siefker-Radtke AO, Dinney CP, Abrahams NA, et al. Evidence supporting preoperative chemotherapy for small cell carcinoma of the bladder: a retrospective review of the M. D. Anderson cancer experience. J Urol. 2004;172:481-4. PMid:15247709. http://dx.doi.org/10.1097/01.ju.0000132413.85866.fc

15. Ismaili N, Arifi S, Flechon A, et al. Small cell cancer of the bladder: pathology, diagnosis, treatment and prognosis. Bull Cancer. 2009;96:e30-44. http://dx.doi.org/10.1684/ bdc. 2009.0883

16. Abrahams NA, Moran C, Reyes AO, et al. Small cell carcinoma of the bladder: a contemporary clinicopathological study of 51 cases. Histopathology. 2005;46:57-63. PMid:15656887. http://dx.doi.org/10.1111/j.1365-2559.2004.01980.x

17. Ismaili N, Ghanem S, Mellas N, et al. Small cell carcinoma of the urinary bladder: a case report and review of the literature. J Cancer Res Ther. 2009;5:133-6. PMid:19542673. http:// dx.doi.org/10.4103/0973-1482.52790

18. Serrano FA, MD, Sánchez-Mora N, Arranz JA, et al. Large Cell and Small Cell Neuroendocrine Bladder Carcinoma. Am J Clin Pathol. 2007;128:733-9. PMid:17951193. http:// dx.doi.org/10.1309/HTREM6QYQDYGNWYA

19. Engles CD, Slobodov G, Buethe DD, et al. Primary mixed neuroendocrine carcinoma of the bladder with large cell component: a case report and review of the literature. Int Urol Nephrol. 2012;44:1021-5. PMid:22392568. http://dx.doi. org/10.1007/s11255-012-0148-6

20. Martín IJ, Vilar DG, Aguado JM, et al. Large cell neuroendocrine carcinoma of the urinary bladder. Bibliographic review. Arch Esp Urol. 2011;64:105-1. PMid:21399243. 
